\title{
A Preliminary Study of the Distributed Maximum Power Point Tracker Designs for Different Types of Solar Cells in Solar and Electric Vehicle Arrays
}

\author{
Quan Li and Peter Wolfs \\ Central Queensland University \\ Rockhampton Mail Center, QLD 4702, Australia
}

\begin{abstract}
For solar and electric vehicles a highly distributed Maximum Power Point Tracking (MPPT) scheme is preferred. A maximum power point tracker has been previously presented for a single triple junction cell. The Texas Instruments MSP430 microprocessor, which is designed for $1.8-\mathrm{V}$ applications, provides the tracking intelligence. However, the Maximum Power Point (MPP) cell voltages of other cell types under different environmental conditions may fall well below $1.8 \mathrm{~V}$. This paper conducts a preliminary study of four maximum power point tracker designs for different cell types, which cover an input supply voltage range from $0.3 \mathrm{~V}$ to $3.0 \mathrm{~V}$. A comparison of the applications, the topologies and the costs of the four designs is summarised at the end of the paper.
\end{abstract}

\section{INTRODUCTION}

Hybrid and electric vehicles have been proposed as the longterm solution in the automotive industry to tackle the shortage of the conventional energy resources and their harmful impact on the natural environment [1], [2]. Customers start to see more hybrid and electric vehicles in the market and $12 \%$ of light vehicles sales in 2025 are predicted to be hybrids [1]. Vehicle mounted solar arrays can always contribute to the energy input and serve as the range extender in the hybrid and electric vehicles [3], [4].

A maximum power point tracker has been previously developed for the single high performance triple junction solar cell for hybrid and electric vehicle applications. To obtain good Maximum Power Point Tracking (MPPT) performances, a highly distributed MPPT scheme is preferred. The Maximum Power Point (MPP) cell voltages of the triple junction cells under a range of temperature and insolation conditions are greater than $1.8 \mathrm{~V}$ [5]. This allows the single triple junction cell to supply the Texas Instrument MSP430 microprocessor, which is designed for $1.8-\mathrm{V}$ applications. However, the MPP cell voltages of other cell types under different environmental conditions may fall well below $1.8 \mathrm{~V}$. As the microprocessor operating below $1.8 \mathrm{~V}$ is not readily available, this requires prior charge pump circuitry to boost the cell voltage level to a level higher than $1.8 \mathrm{~V}$ in order to drive the microprocessor.

This paper conducts a preliminary study of the maximum power point tracker designs for different cell types including the triple, the dual and the silicon junction cells. Different designs employ the same MSP430 microprocessor to allow the software to be easily transplanted. A total of four designs are proposed to cover an input supply voltage range from $0.3 \mathrm{~V}$ to $3.0 \mathrm{~V}$. The design considerations are discussed in detail for all four circuits. Finally, a comparison of the four designs is provided in terms of their applications, topologies and costs.

\section{INDUCTORLESS BUCK CONVERTER}

The buck converter topology is employed in the individual maximum power point tracker. As the vehicle array may consist several hundred solar cells, a highly distributed MPPT scheme leads to a large number of buck converters to be connected in series and operate asynchronously as shown in Fig. 1 [6], [7]. The important advantage of this design is that the individual buck converter features an inductorless topology and all converters share a single inductor on the load side. This results in a more compact, cost effective and power efficient design for the individual maximum power point tracker.

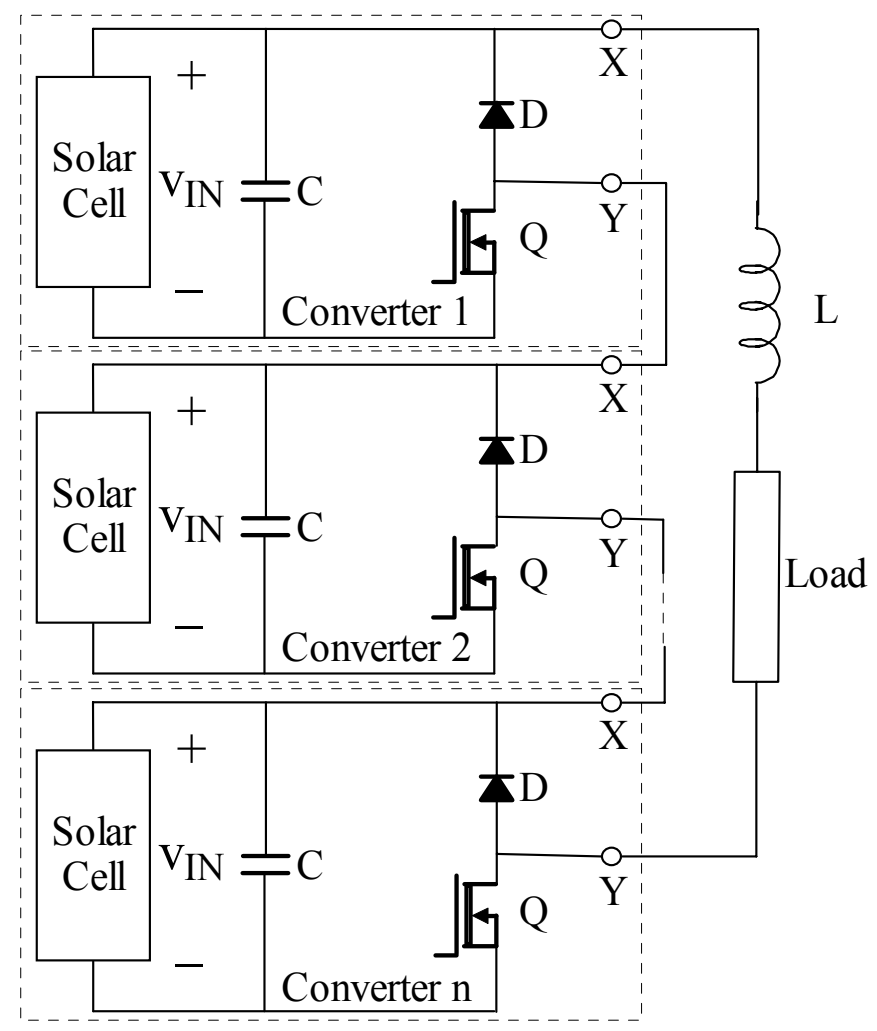

Fig. 1. Asynchronously Switching Buck Converters 


\section{TRACKER Design FOR ONE TRIPLE JunCtiOn CELL}

Fig. 2 shows the converter design for the single Gallium Arsenide triple junction cell. This MPPT circuit design can be employed in the applications where the input voltage is between $1.8 \mathrm{~V}$ and $3 \mathrm{~V}$.

As mentioned previously in the paper, a key feature of this design is that the microprocessor is directly driven by the cell and no prior charge pump circuit is required. The microprocessor handles the following three main tasks:

- Providing two complementary high frequency square waveforms to drive the four-stage charge pump circuit made of capacitors and diodes.

- Sensing the cell output voltage through a voltage divider made up of two $100-\mathrm{k} \Omega$ resistors and converting the voltage readings to the digital values through the embedded 10-bit Analogue Digital Converter (ADC).

- Executing both the MPPT algorithm and ProportionalIntegraland (PI) control in order to generate the PulseWidth Modulated (PWM) gate signals for the MOSFET driver chip.

In the component selection process, other than the requirement for surface mount components, the following issues must also be considered:

- The input capacitor of $200 \mu \mathrm{F}$ must be either tantalum or ceramic capacitors due to their low Equivalent Series Resistances (ESR). Ceramic capacitors are preferred as they are non-polarised and have a longer lifetime. However, the cost might be significantly higher since the technology in manufacturing $100-\mu \mathrm{F}$ ceramic chip capacitors is reasonably new. Therefore tantalum capacitors may be the best candidate available.

- All diodes must be Schottky diodes in order to reduce the reverse recovery losses. Additionally, the diodes used in the charge pump circuit require low junction capacitance to minimise the power loss during the reverse blocking state.

- The MOSFET gate driver is better to be equipped with a push pull output so that a pull-up resistor is not needed.

- The MOSFETs must have both low drain source on resistance and total gate charge to minimise both the gate driving and the conduction power losses.

In the circuit design, the MOSFET gate driver chip requires a minimum supply voltage of $2.7 \mathrm{~V}$ and the MOSFET gate threshold voltage is as low as $1 \mathrm{~V}$. It will suffice to employ a two-stage diode capacitor charge pump circuit. However, a higher voltage around $5 \mathrm{~V}$ is preferred as the MOSFET drain source on resistance will drop when the gate voltage increases. Also an arrangement is made that the bottom MOSFET is chosen to be the control MOSFET as the gate voltage of that MOSFET is higher.

\section{TRACKer Design For One DuAl OR TRIPLE JUNCTION CELL}

Fig. 3 shows the converter design for the single Gallium Arsenide dual junction or triple junction cell. This MPPT design can be employed in the applications where the input voltage is between $1.6 \mathrm{~V}$ and $3 \mathrm{~V}$. A fundamental change has been made in this design where the microprocessor is supplied through the charge pump circuit driven by an oscillator based on an extra low-voltage inverter or Schmitt trigger. The output of the four-stage diode capacitor charge pump circuit supplies power directly to the MOSFET driver. As this voltage is higher than the maximum supply voltage of the microprocessor of 3.6 $\mathrm{V}$, a step down voltage regulator is used.

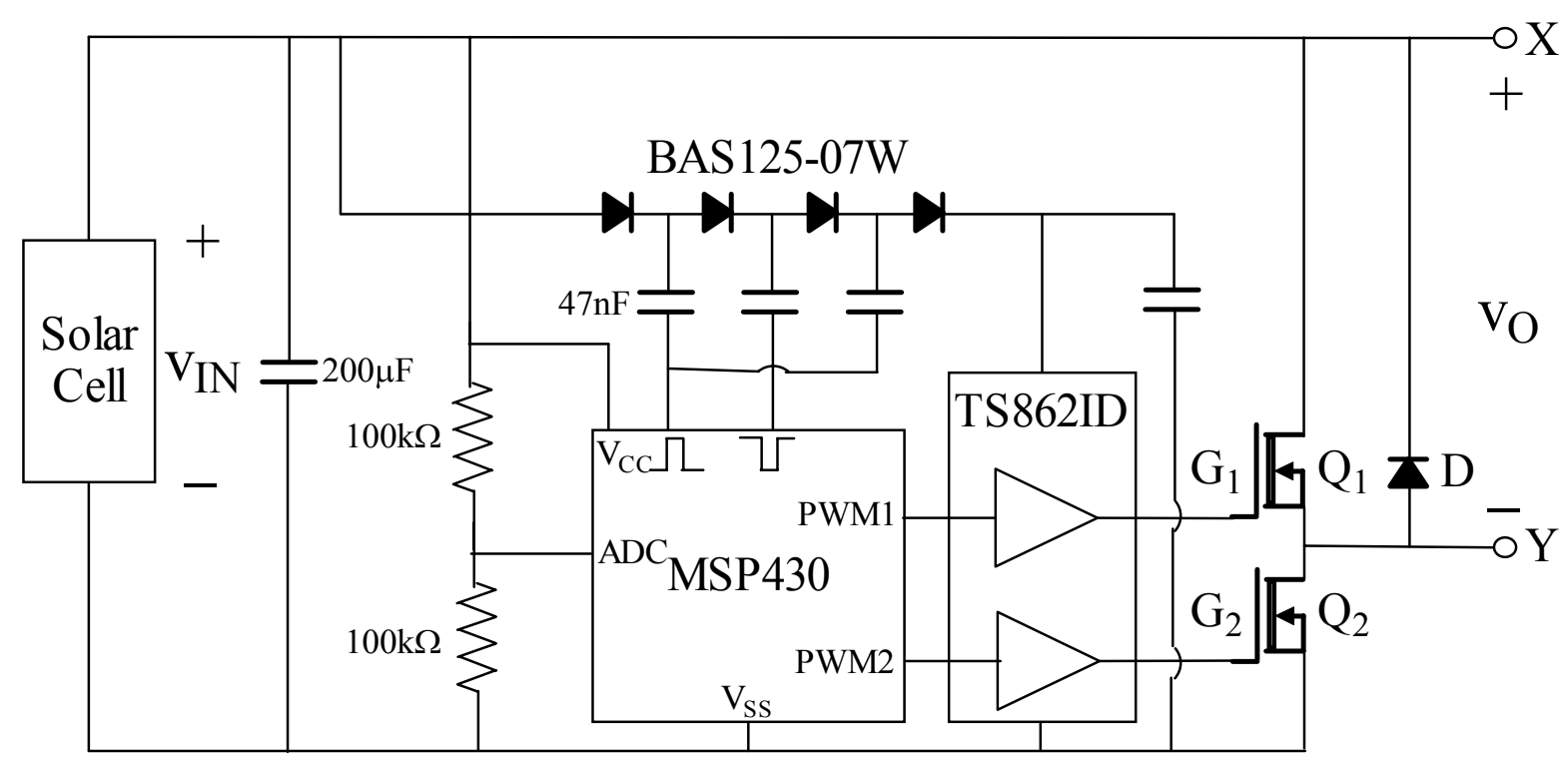

Fig. 2. MPPT Circuit Diagram for One Triple Junction Cell (Design A) 


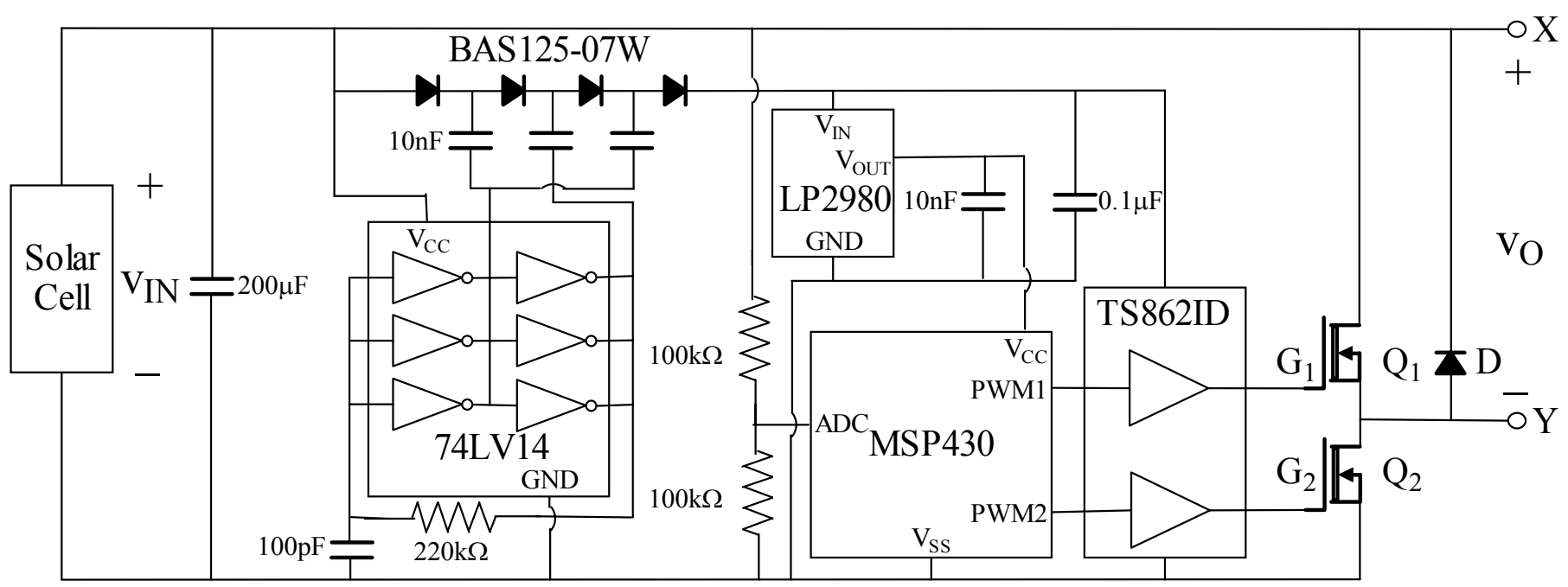

Fig. 3. MPPT Circuit Diagram for One Dual or Triple Junction Cell (Design B)

In recent years, extra low-voltage CMOS logic semiconductor families have been developed by several manufacturers that operate at around $1 \mathrm{~V}$. They include Fairchild Semiconductor NC7NP04/ NC7NP14, Philips Semiconductors 74LV04/74LV14 and Texas Instruments SN74AUC04/SN74AUC14. However, most of these CMOS designs are very sensitive to the slow input edge rates and cannot function properly when the oscillation is below the Megahertz frequency range. In order to minimise the power loss inside the charge pump circuit, an oscillation frequency in the kilohertz range is preferred and Philips Semiconductors 74 LV14 is selected due to its longer proportional delay time [8].

Although in this case the oscillator 74LV14 is operable in the input voltage range from $1 \mathrm{~V}$ to $5.5 \mathrm{~V}$, any input voltage lower than $1.6 \mathrm{~V}$ is unlikely to work and this lower voltage limit on this MPPT design is imposed by the MOSFET driving requirements to obtain a lower drain source on resistance. Theoretically, the charge pump shown in Fig. 3 produces four times the cell voltage to drive both the microprocessor power supply and the MOSFET driver circuit and it is possible to further extend the voltage range by increasing the number of stages in the diode capacitor charge pump circuit. However, a Schottky diode has a typical forward voltage drop of $0.3 \mathrm{~V}$ and this limits the performance of the charge pump circuit when the number of stages increases. Seven or eight stages of the charge pump circuit are required to converter a $1-\mathrm{V}$ input voltage to around $5-\mathrm{V}$ output voltage. In addition, the power loss in the charge pump will be higher when the number of stages increases.

The selected step down voltage regulator LP2980 is able to supply a maximum output current of $50 \mathrm{~mA}$ to the load and dissipates only $375 \mu \mathrm{A}$ through the ground pin [9].

Both LV7414 and LP2980 are available in miniaturised packages so that the size of the MPPT hardware will not be significantly increased compared with that in Fig. 2. The size of the 14-pin TSSOP package of LV7414 is $3.1 \mathrm{~mm} \times 5.1 \mathrm{~mm}$
( 0.12 in $\times 0.20$ in) and that of the 5-pin M5 package of LP2980 is $2.8 \mathrm{~mm} \times 2.9 \mathrm{~mm}(0.11 \mathrm{in} \times 0.12 \mathrm{in})$.

\section{TRACKER DESIGN FOR THREE OR FOUR SILICON JUNCTION CELLS}

Fig. 4 shows the converter design for three or four silicon cells. This MPPT design can be employed in the applications where the input voltage is between $0.9 \mathrm{~V}$ and $1.8 \mathrm{~V}$. The microprocessor is powered by the Texas Instruments TPS60310, which is a high efficiency charge pump capable of producing a $3.3 \mathrm{~V}$ output from an input from $0.9 \mathrm{~V}$ to $1.8 \mathrm{~V}$ [10]. The device uses two cascaded flying capacitor multipliers and MOSFETs rather than diodes as the switching elements to avoid the diode forward drop limitation that is inherent in the diode capacitor charge pumps. The microprocessor still needs to provide additional charge pumping to drive the MOSFETs as shown in Fig. 2 however only two stages of diode capacitor charge pump circuit are required.

The 10-pin TPS60310 is available in a compact MSOP package, which has a physical size of $3.05 \mathrm{~mm} \times 4.98 \mathrm{~mm}$ $(0.12$ in $\times 0.20$ in $)$. The charge pump chip requires only four additional $1-\mu \mathrm{F}$ capacitors therefore the size of this design should be definitely comparable with the original design shown in Fig. 2.

\section{TRACKER DESIGN FOR ONE OR TWO Silicon JunCTION CELLS}

Fig. 5 shows the converter design for one or two silicon cells. This MPPT design can be employed in the applications where the input voltage is between $0.3 \mathrm{~V}$ and $1.2 \mathrm{~V}$. The key feature of this design is the use of the Seiko Instruments S$882 \mathrm{Z}$ series charge pump [11]. This charge pump utilizes depletion mode silicon on insulator MOSFETs to produce a charge pump with an operational voltage compatible with a single silicon cell. The originally intended application is the solar powered wrist watches. The charge pump only develops 
approximately $30 \mu \mathrm{W}$ of power and is only intended as a jump start device for a larger converter of a few milliwatts rating, in this case, an S-8353D30MC based boost converter [12]. This powers the microprocessor which still needs to perform additional charge pumping through diode capacitor arrangement to drive the switching MOSFETs. The datasheet of the boost converter recommends the external inductor of Sumida Corporation CDRH8D28-101 and the external diode of Matsushita Electronic Components MA2Z748 [12] but they can also be substituted by similar surface mount components from other manufacturers.

A significant difference between this converter and the previous three designs is that it does require an inductor to boost an input of $0.3 \mathrm{~V}$ to an output of $3 \mathrm{~V}$ although inductors should generally be avoided in terms of the cost. However, if surface mount inductors are employed, the device is small and would not increase the size and the cost of the MPPT hardware significantly. It is worth mentioning that the charge pump arrangement with diodes and capacitors as used for supplying the power to the microprocessor in Fig. 3 will be completely impossible for this design as the diode forward voltage drops are in the order of $0.3 \mathrm{~V}$.

The charge pump S- $882 \mathrm{Z}$ and the boost converter S$8353 \mathrm{D} 30 \mathrm{MC}$ are both available in 5-pin SOT23 package with a size of $2.8 \mathrm{~mm} \times 2.9 \mathrm{~mm}(0.11 \mathrm{in} \times 0.11 \mathrm{in})$ and the size of this design will not be increased significantly.

\section{COMPARISON OF FOUR TRACKER DESIGNS}

The majority of the components in the above four MPPT converter designs are available from three suppliers including Avnet, Digi-Key and Newark InOne [13]-[15]. The charge pump S-882Z and the boost converter S-8353D30MC can be respectively purchased from Seiko Singapore and Mouser Electronics [16], [17]. The cost of the key components in the four converter designs are listed in Table I.

The unit prices in Table I are based on an order quantity of 10,000 units. The actual cost of the individual MPPT hardware will be slightly higher than those listed in Table I considering the ancillary surface mount component cost as well as the Printed Circuit Board (PCB) manufacturing cost.

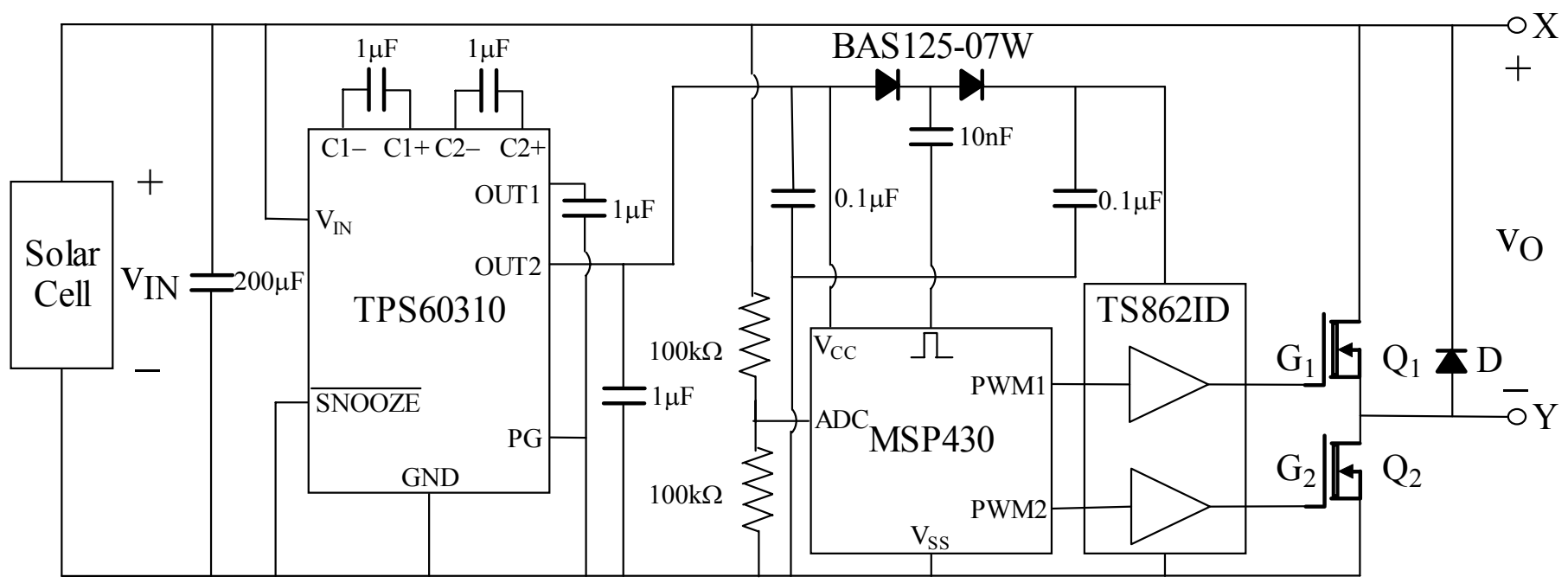

Fig. 4. MPPT Circuit Diagram for Three or Four Silicon Junction Cells (Design C)

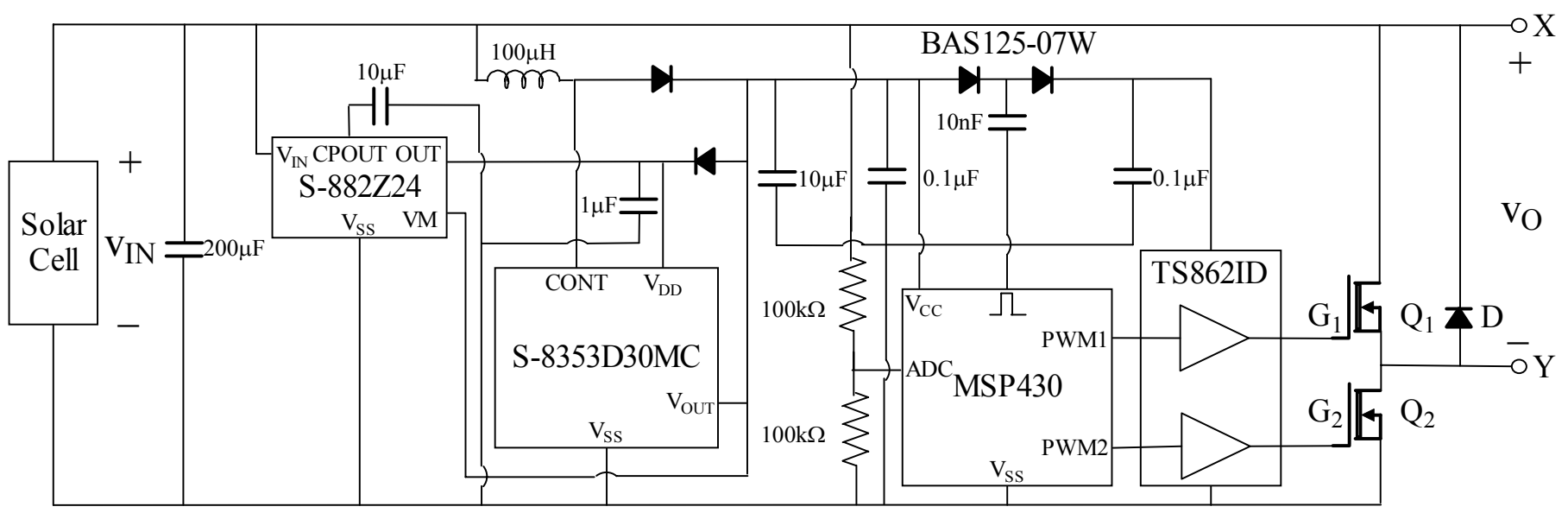

Fig. 5. MPPT Circuit Diagram for One or Two Silicon Junction Cells (Design D) 
TABLE I

Key Component Costs In the MPPT HaRdware

\begin{tabular}{|c|c|c|c|c|c|c|c|c|}
\hline \multirow{2}{*}{ Component } & \multirow{2}{*}{ Manufacturer } & \multirow{2}{*}{$\begin{array}{c}\text { Part } \\
\text { Number }\end{array}$} & \multirow{2}{*}{$\begin{array}{l}\text { Unit Price } \\
\text { (US\$) }\end{array}$} & \multirow{2}{*}{ Supplier } & \multicolumn{4}{|c|}{ Number of Components Required } \\
\hline & & & & & Design A & Design B & Design C & Design D \\
\hline Microprocessor & Texas Instrument & MSP430F1122IPW & 2.40 & Avnet & 1 & 1 & 1 & 1 \\
\hline Input Capacitor & AVX Corporation & TPSC107K006R0150 & 0.286 & Avnet & 2 & 2 & 2 & 2 \\
\hline 0.9-V Charge Pump & National Semiconductor & TPS60310DGSR & 1.26 & Avnet & 0 & 0 & 1 & 0 \\
\hline 0.3-V Charge Pump & Seiko Instruments & S-882Z & 0.71 & Seiko Singapore & 0 & 0 & 0 & 1 \\
\hline Boost Converter & Seiko Instruments & S-8353D30MC & 0.389 & Mouser Electronics & 0 & 0 & 0 & 1 \\
\hline Charge pump Diodes & Infineon & BAS125-07W & 0.1432 & Avnet & 2 & 2 & 1 & 1 \\
\hline MOSFET Driver & STMicro-electronics & TS862ID & 0.806 & Digi-Key & 1 & 1 & 1 & 1 \\
\hline${\text { MOSFETs } Q_{1} \text { and } Q_{2}}$ & International Rectifier & IRF7821PBF & 0.408 & Avnet & 2 & 2 & 2 & 2 \\
\hline Diode D & International Rectifier & 10BQ015 & 0.066 & Digi-Key & 1 & 1 & 1 & 1 \\
\hline Voltage Regulator & National Semiconductor & LP2980AIM5-2.5 & 0.23375 & Newark InOne & 0 & 1 & 0 & 0 \\
\hline Schmitt Trigger & Philips Semiconductors & 74LV14D & 0.102 & Avent & 0 & 1 & 0 & 0 \\
\hline Total Cost (US\$) & - & - & - & - & 4.95 & 5.28 & 6.06 & 5.90 \\
\hline
\end{tabular}

TABLE II

COMPARISON OF FOUR MPPT CONVERTER DESIGNS

\begin{tabular}{|c|c|c|c|c|}
\hline Design & $\mathrm{A}$ & $\mathrm{B}$ & $\mathrm{C}$ & $\mathrm{D}$ \\
\hline Input Voltage Range (V) & $1.8-3.0$ & $1.6-3.0$ & $0.9-1.8$ & $0.3-1.2$ \\
\hline $\begin{array}{c}\text { Target } \\
\text { Solar Cell Types }\end{array}$ & $\begin{array}{c}\text { One } \\
\text { triple junction cell }\end{array}$ & $\begin{array}{c}\text { One } \\
\text { dual or triple junction cell }\end{array}$ & $\begin{array}{c}\text { Three or four } \\
\text { silicon junction cells }\end{array}$ & $\begin{array}{c}\text { One or two } \\
\text { silicon junction cells }\end{array}$ \\
\hline $\begin{array}{c}\text { Charge Pump } \\
\text { for Microprocessor }\end{array}$ & $\begin{array}{l}\text { Not } \\
\text { required }\end{array}$ & $\begin{array}{c}\text { 74LV14D } \\
\text { with diodes and capacitors }\end{array}$ & $\begin{array}{c}\text { TPS60310 } \\
\text { with capacitors }\end{array}$ & $\begin{array}{c}\text { S-882Z and S-8353D30MC } \\
\text { with inductor }\end{array}$ \\
\hline $\begin{array}{c}\text { Number of Stages of the Diode Capacitor } \\
\text { Charge Pump for MOSFET Driver }\end{array}$ & 4 & 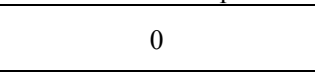 & 2 & ( \\
\hline Estimated Cost (US\$) & 4.95 & 5.28 & 6.06 & 5.90 \\
\hline PCB Size $\left(\mathrm{mm}^{2}, \mathrm{in}^{2}\right)$ & $378,0.59$ & $\mathrm{~N} / \mathrm{A}$ & $357,0.55$ & N/A \\
\hline Efficiency $(\%)$ & 96.2 & N/A & 93.9 & N/A \\
\hline
\end{tabular}

In the design of the MPPT hardware, there are several challenges including:

- Reasonable cost and small Printed Circuit Board (PCB) size so that the hardware can be easily integrated with single or a small number of solar cells.

- Low power loss or high power conversion efficiency as the converter power rating is typically less than one watt.

Among the four MPPT converter designs, Designs A and C have been implemented in the laboratory. A summary of the four MPPT converter designs is provided in Table II. It can be shown that the individual designs can achieve a price between $\$ 5$ and \$6 US. The MPPT hardware can be minimized to a size less than $400 \mathrm{~mm}^{2}\left(0.62 \mathrm{in}^{2}\right)$ and this allow them to be readily integrated to the single cell or the cell group.

\section{VIII.CONCLUSIONS AND FUTURE WORK}

The four MPPT converter designs shown in Figs. 2 to 5 cover a broad input voltage range from $0.3 \mathrm{~V}$ to $3 \mathrm{~V}$. They are suitable for a variety of solar cells including GaAs triple junction cells, GaAs dual junction cells and silicon junction cells. The topologies of the individual converter designs are discussed in detail with a main focus of the charge pump circuit design to supply the microprocessor MSP430. At the end of the paper, the four converter designs are compared with regards to their applications, topologies, costs, PCB sizes and efficiencies.

As mentioned earlier in the paper, Designs $\mathrm{A}$ and $\mathrm{C}$ have been produced in the laboratory. The future work involves the production of Designs B and D and they will be compared with Designs $\mathrm{A}$ and $\mathrm{C}$. The static and dynamic tracking performances of Design A and $\mathrm{C}$ have also been established by the analogue solar cell simulator. One potential problem with Design $\mathrm{A}$ is that the microprocessor will shut down under extremely low insolation levels since the cell voltage tends to drop below $1.8 \mathrm{~V}$. It is expected that Designs $\mathrm{B}$ and $\mathrm{C}$ can be employed to rectify the problem and this is another area of the future work.

\section{ACKNOWLEDGEMENT}

This work was supported by the Queensland Department of Public Works and Housing and the Queensland Department of Transport.

\section{REFERENCES}

[1] J. Voelcker, "Top 10 tech cars 2007, electric cars are back," IEEE Spectr., Vol. 44, No. 4, pp. 34-41, Apr. 2007.

[2] C. C. Chan, "The state of the art of electric, hybrid, and fuel cell vehicles," Proc. IEEE, Vol. 95, No. 4, pp. 704-718, Apr. 2007.

[3] J. Voelcker, "Top 10 tech cars, hybrids square off against diesels for the economy laurels," IEEE Spectr., Vol. 43, No. 4, pp. 24-33, Apr. 2006.

[4] A. Simpson, G. Walker, M. Greaves, D. Finn and B. Guymer, "The ultra commuter: a viable and desirable solar powered commuter vehicle," in Proc. Australasian Universities Power Engineering Conference, 2002.

[5] Spectrolab Inc. (2002, May). 25.1\% GaInP2/GaAs/Ge triple junction solar cells. [Online]. Available: http://www.spectrolab.com/DataSheets/ TJCell/tj.pdf

[6] P. Wolfs, L. Tang and S. Senini, "Distributed maximum power tracking for high performance vehicle solar arrays," in Proc. Australasian Universities Power Engineering Conference, 2004.

[7] P. Wolfs and L. Tang, "A single cell maximum power point tracking converter without a current sensor for high performance vehicle solar arrays," in Proc. IEEE PESC, 2005, pp. 165-171. 
[8] Philips Semiconductors. (1998, Apr.). 74LV14 Datasheet. [Online]. Available: http:/www.standardics.nxp.com/products/lv/datasheet/ 74lv14.pdf

[9] National Semiconductor. (2006, Sept.). LP2980 micropower $50 \mathrm{~mA}$ ultra low-dropout regulator in SOT-23 and micro SMD packages. [Online]. Available: http://cache.national.com/ds/LP/LP2980.pdf

[10] Texas Instrument. (2006, Feb.). TPS60310, TPS60311, TPS60312, TPS60313 single-cell to 3-V/3.3-V, 20-mA dual output, high-efficiency charge pump with snooze mode. [Online]. Available: http://focus.ti.com/ lit/ds/symlink/tps60310.pdf
[11] Seiko Instruments Inc. S-882Z Series Datasheet. [Online]. Available: $\mathrm{ftp} / / / \mathrm{ftp}$. sii.co.jp/pub/ic/spd_dtst/dt_sht_e/charge_p/S882Z_E.pdf

[12] Seiko Instruments Inc. S- $\mathbf{S} 353 / 83 \overline{54}$ Series Datasheet. [Online]. Available: ftp://ftp.sii.co.jp/pub/ic/spd_dtst/dt_sht_e/swi_regu/ S8353 8354 E.pdf

[13] Avnet, Inc. [Önline]. Available: https://www.em.avnet.com

[14] Digi-Key Corporation. [Online]. Available: http://www.digikey.com

[15] Newark InOne. [Online]. Available: http://www.newark.com

[16] Seiko Instruments Singapore. [Online]. Available: http://www.sii.com.sg

[17] Mouser Electronics. [Online]. Available: http://www.mouser.com 